\title{
Fermentação de esterco de suínos para uso como adubo orgânico
}

\author{
Maria A. N. Sediyama', Sanzio M. Vidigal ${ }^{1}$, Marinalva W. Pedrosa ${ }^{1}$, Cláudia L. O. Pinto ${ }^{1}$ \& Luís T. Salgado ${ }^{1}$
}

\section{RESUMO}

Os principais objetivos deste trabalho, foram: avaliar o processo de fermentação do esterco sólido de suínos, fazer a caracterização física, química e microbiológica dos adubos orgânicos produzidos e identificar o tempo ideal de fermentação. Esterco sólido de suínos, proveniente da separação mecânica, foi arranjado em pilhas de 2,0 $\mathrm{m}^{3}$, sem cobertura e com cobertura com lona plástica e as pilhas foram revolvidas quinzenalmente e umedecidas sempre que necessário, com monitoramento diário da temperatura. Pela análise das características temperatura, relação C: $\mathrm{N} \mathrm{e} \mathrm{pH}$, verificou-se que o tempo de fermentação de 65 dias foi suficiente para maturação do esterco com características químicas e físicas adequadas. Houve aumento na concentração de nutrientes, exceto do zinco, durante a fermentação, o que melhorou a qualidade do esterco de suínos. O período de 84 dias de fermentação foi suficiente para reduzir a população de coliformes, da ordem de $99,90 \%$, comparada com população inicial. Não foi constatada a presença de Salmonella sp e Listeria monocytogenes em nenhuma das amostras do esterco de suínos em fermentação.

Palavras-chave: dejeto de suínos, estabilização, nutrientes, microbiota, sanidade

\section{Fermentation of pig manure for use as an organic fertilizer}

\begin{abstract}
This research had the objectives of evaluating the fermentation process of solid pig manure, performing the physical, chemical and microbiological characterization of organic fertilizers produced and identifying the ideal time of fermentation. Solid pig manure, derived from mechanical separation, was arranged in heaps of $2.0 \mathrm{~m}^{3}$ with, and without, plastic covering. The heaps were turned every fifteen days and watered whenever necessary, with daily control of temperature. By the analysis of the characteristics of temperature, $\mathrm{C}: \mathrm{N}$ ratio and $\mathrm{pH}$, it was verified that the time of fermentation of 65 days was sufficient for maturation of the pig manure with appropriate chemical and physical characteristics. There was an increase in the concentration of nutrients, except for zinc, during the fermentation, which improved the quality of the pig manure. The period of 84 days of fermentation was sufficient to reduce the population of coliforms by $99.90 \%$ compared to the initial population. The presence of Salmonella sp and Listeria monocytogenes was not verified in any of the fermentation samples of pig manure.
\end{abstract}

Key words: pig manure, stabilization, nutrients, microbiology, sanity 


\section{INTRODUÇÃO}

O Estado de Minas Gerais possui o segundo maior rebanho de suínos do Brasil e uma suinocultura de alta tecnologia, com a criação de animais em regime de confinamento. Esta atividade é muito importante para a economia do estado, pois garante produção e renda, além de gerar empregos e estabilidade social; entretanto, constitui uma atividade concentradora de resíduos orgânicos de alto potencial poluidor; assim, em função do grande volume de resíduos orgânicos produzidos, especialmente na região da Zona da Mata, temse enfatizado estudos com o objetivo de reduzir a poluição ambiental, reciclar e aproveitar os nutrientes.

Esses resíduos são eficazes para promover a adubação do solo e a nutrição das plantas ou mesmo para complementar a adubação mineral, porém cuidados no manejo desses resíduos são indispensáveis para que a produção de alimentos não seja prejudicada. Os principais cuidados a serem considerados, são: a sanidade dos adubos orgânicos e a aplicação em quantidades adequadas, de forma a evitar prejuízos ao ambiente (Daniel, 2005).

De acordo com Amorim et al. (2005), uma estratégia para o desenvolvimento da suinocultura com menor impacto ambiental ocasionado pela disposição inadequada dos dejetos no ambiente, é a adoção da reciclagem desses resíduos, de forma a permitir geração de energia renovável e/ou a estabilização da matéria orgânica, por meio da fermentação, antes do seu uso como adubo. De acordo com Konzen (1983), o esterco de suínos é constituído pelas fezes dos animais que, normalmente, apresentam-se na forma pastosa ou sólida, enquanto os dejetos são constituídos de fezes, urina, água desperdiçada pelos bebedouros e de higienização, resíduos de ração, pêlos, poeiras e outros materiais decorrentes do processo criatório.

A fermentação da matéria orgânica presente nos estercos é realizada para reduzir ou inativar os microrganismos patogênicos e a toxicidade desses resíduos, antes de serem aplicados ao solo. Os estercos frescos ou não estabilizados podem esquentar e inibir a germinação de sementes e o alongamento de raízes, além de contaminar o operador, o solo e os vegetais. Por outro lado, o uso de esterco maduro pode ter efeito estimulador no crescimento de plantas em função da presença de nutrientes minerais, microrganismos benéficos, substâncias húmicas e as características físicas de um adubo orgânico estabilizado. A estabilidade ou maturidade é característica importante de qualidade para um adubo orgânico (Tam \& Tiquia, 1994; Wu \& Ma, 2001).

Para reduzir os riscos envolvidos na reciclagem dos estercos de suínos, é prudente assegurar um tempo mínimo de fermentação e decomposição desses resíduos antes de usálos como fertilizante. Para cada tipo de resíduo, mecanismos seguros para acelerar a decomposição da matéria orgânica devem ser adotados. Para o dejeto líquido pode-se usar a agitação com motor e hélice para manter a matéria orgânica em movimento, o que permite o aumento da concentração de oxigênio e a multiplicação das bactérias decompositoras. Em se tratando de estercos sólidos, a compostagem constitui um processo muito eficiente e seguro, desde que bem conduzida, levando-se em consideração o binômio tempo e temperatura para que esses resíduos passem por processos de fermentação e a inativação de possíveis contaminantes, além de sua caracterização quanto aos aspectos químicos, físicos e microbiológicos (Matos \& Sediyama, 1995; Matos et al., 1998; Sediyama et al., 2000).

Os estercos de suínos, quando submetidos a fermentação aeróbica, perdem exclusivamente carbono, na forma de $\mathrm{CO}_{2}$, e água, na forma de vapor, resultando em resíduo final de melhor qualidade para uso como adubo orgânico em função do menor teor de umidade, da mineralização do nitrogênio e da solubilização parcial de alguns nutrientes; desta forma, quando aplicados ao solo esses estercos ou adubos orgânicos são eficientes em promover a nutrição das plantas e podem substituir, em parte, ou eliminar a necessidade do uso de adubos minerais na agricultura.

Em vista da diversidade de macronutrientes e micronutrientes contidos nos estercos de suínos e da grande disponibilidade dessa matéria-prima na Zona da Mata Mineira, é de grande importância a realização de estudos sobre a sua qualidade e sanidade para a produção de adubos orgânicos; assim, os objetivos deste trabalho foram avaliar dois processos de fermentação do esterco sólido de suínos, fazer a caracterização física, química e microbiológica dos adubos orgânicos produzidos e identificar o tempo ideal de fermentação para a maturação do esterco de suínos.

\section{MATERIAL E MÉTODOS}

O experimento foi conduzido na Zona da Mata Mineira, na Fazenda Experimental Vale do Piranga, da EPAMIG, em Oratórios, MG, no período de 29 de março a 21 de junho de 2005. A unidade de pesquisa está situada a $20^{\circ} 30^{\prime}$ de latitude $\mathrm{S}$ e $43^{\circ} 00^{\prime}$ de longitude $\mathrm{O}$; a altitude é de $500 \mathrm{~m}$ em relação ao nível do mar, com temperatura média máxima anual de $21,8^{\circ} \mathrm{C}$ e mínima anual de $19,5^{\circ} \mathrm{C}$; a precipitação média anual é de $1.250 \mathrm{~mm}$. Segundo Köppen, o clima da região varia do tipo Cwa, tropical úmido a Aw, semi-úmido de verões quentes e a vegetação natural era de floresta tropical semidecidual ou ombrofila mista (Cunha et al., 2000).

O esterco sólido de suínos usado na pesquisa proveio de uma granja localizada no município de Urucânia, MG, que usava o método de separação dos dejetos sólido e líquido em peneira mecânica, cujo material foi transportado para o pátio de compostagem, onde foram confeccionadas oito pilhas com 2,0 $\mathrm{m}^{3}$ de esterco sólido com umidade inicial de $70 \%$, dispostas eqüidistantemente. Os tratamentos se compuseram de dois sistemas de condução das pilhas: sem cobertura e com cobertura com lona plástica de cor amarela, com quatro repetições, no delineamento inteiramente ao acaso. Durante o estudo se levantaram sete amostragens de esterco em cada tratamento, para as análises física e química (0, 7, 14, 28, 42, 56 e aos 84 dias); já para as análises microbiológicas foram realizadas quatro amostragens $(0,16,64$ e aos 84 dias); as amostras, com aproximadamente $400 \mathrm{~g}$ de esterco, foram coletadas em diferentes pontos no interior das pilhas e, em seguida, transportadas para os laboratórios em caixas de isopor. 
A umidade nas amostras de esterco foi definida pela diferença da massa do material fresco (MF) menos a do material seco (MS) vezes 100 dividido pela massa de material fresco $[\%$ Umidade $=($ MF-MS $) \times 100 / M F]$. Fez-se a secagem do esterco em estufa com circulação de ar a $70{ }^{\circ} \mathrm{C}$, durante 72 h; em seguida, procederam-se às análises químicas das amostras, para pH, carbono orgânico, nitrogênio e fósforo; potássio; cálcio, magnésio, enxofre e cobre; manganês, ferro e zinco, conforme metodologia descrita em Silva (1999). A temperatura no interior das pilhas foi monitorada diariamente, às 9 e às 15 h, com termômetro manual de haste longa e graduação de 0 a $100{ }^{\circ} \mathrm{C}$, durante todo o processo. As pilhas foram revolvidas manualmente, com enxada, em intervalos de quinze dias, quando se fez o umedecimento do esterco em fermentação, especialmente nas pilhas descobertas.

Amostras de $10 \mathrm{~g}$ de dejetos foram diluídas e submetidas a contagem de bactérias do grupo coliformes totais e coliformes fecais ou termotolerantes, pela técnica do Número Mais Provável - NMP (APHA, 1992; Silva et al., 1997) e à pesquisa de Salmonella sp (APHA, 1992). A pesquisa de Listeria monocytogenes foi realizada em 25 g de amostra; para isto, as amostras foram enriquecidas em Listeria Enrichmet Broth (Biolife), durante $48 \mathrm{~h}$, a $37^{\circ} \mathrm{C}$; após o enriquecimento realizou-se a semeadura em Ágar Listeria ACC (ALOA) e as placas foram incubadas $48 \mathrm{~h}$ a $37^{\circ} \mathrm{C}$.

Os resultados das análises químicas e físicas foram submetidos à análise de variância e regressão, tendo como variável independente o tempo de fermentação, expresso em dias.

\section{RESULTADOS E DISCUSSÃO}

Durante o período de fermentação, que foi de 84 dias, não houve necessidade de se umedecer as pilhas de esterco manejadas com cobertura, porém no tratamento em que as pilhas permaneceram descobertas ocorreu maior desidratação. Neste tratamento se ressentiu da necessidade de umedecimento do esterco, para manter a umidade necessária à atividade microbiana; ainda assim, notou-se redução significativa $(\mathrm{P}<0,01)$ no teor de umidade do dejeto durante o processo de fermentação (Figura 1A); no tratamento com cobertura observaram-se maiores percentagens de umidade durante o período de fermentação do esterco e, no tratamento sem cobertura, o menor teor de umidade estimado foi de 33,97\%, aos 51 dias de fermentação chegando, ao final do processo, com $44,75 \%$ de umidade. Teores de umidade abaixo de $40 \%$ reduzem a atividade microbiana, principalmente de bactérias, sendo que umidade abaixo de $30 \%$ constitui fator limitante para a decomposição e abaixo de $12 \%$ praticamente cessa toda a atividade biológica. A umidade ótima para compostagem da matéria orgânica é de $50 \%$ com limites desejáveis máximo de $60 \%$ e mínimo de $40 \%$ (Kiehl, 1985). De acordo com Tiquia (2005), se o teor de umidade for mantido semanalmente a $60 \%$, no turno de regas de quatro dias o dejeto de suínos alcança a maturação com 56 dias.

Constataram-se, durante o processo de fermentação, temperaturas superiores nas pilhas de esterco sem cobertura, às 9 e às 15 h, em relação ao tratamento coberto. O comporta- mento da temperatura foi bem definido, semelhante ao padrão de outros resíduos orgânicos, ou seja, temperaturas mais altas no início do processo, seguidas de redução e, no final, tendência à estabilização (Figura 1B); notou-se, no tratamento com cobertura, redução da temperatura durante todo o período de fermentação, às 9 e às $15 \mathrm{~h}$. Com aproximadamente 60 dias de fermentação, nos dois tratamentos a temperatura média no interior das pilhas foi praticamente igual à do ambiente, indicando estabilização do processo de fermentação (Figura 1B e C).
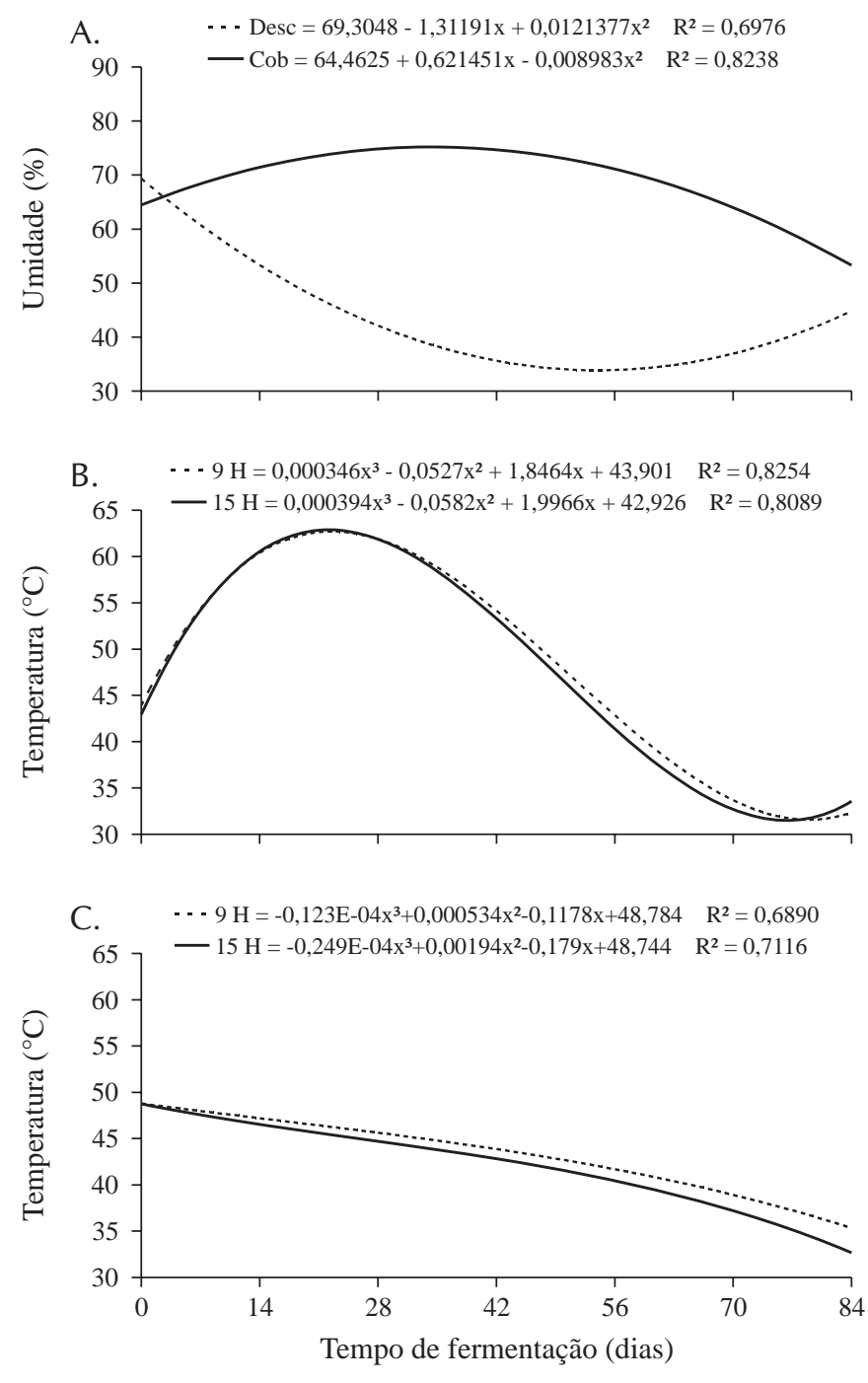

Figura 1. Percentual de umidade do esterco de suínos nos tratamentos sem cobertura e com cobertura (A) e variação da temperatura no interior das pilhas de esterco de suínos nos tratamentos sem cobertura (B) e com cobertura $(\mathrm{C})$, durante o período de fermentação

Observou-se, ao longo do período de fermentação, elevação no teor dos nutrientes $\mathrm{N}, \mathrm{P}, \mathrm{K}, \mathrm{Ca}, \mathrm{Mg}$ e S com o aumento do tempo de fermentação sem, contudo, apresentar diferenças significativas para os tratamentos com e sem cobertura das pilhas (Figura 2A, B, C, D, E e F); no tratamento descoberto, $\mathrm{N}, \mathrm{P}, \mathrm{K}$ e Ca atingiram teores máximos com menor tempo de fermentação; o teor máximo de $\mathrm{N}$ foi estimado em 28,01 e 28,55 $\mathrm{g} \mathrm{kg}^{-1}$ aos 62 dias de fermentação no tratamento descoberto e aos 84 dias no coberto, 

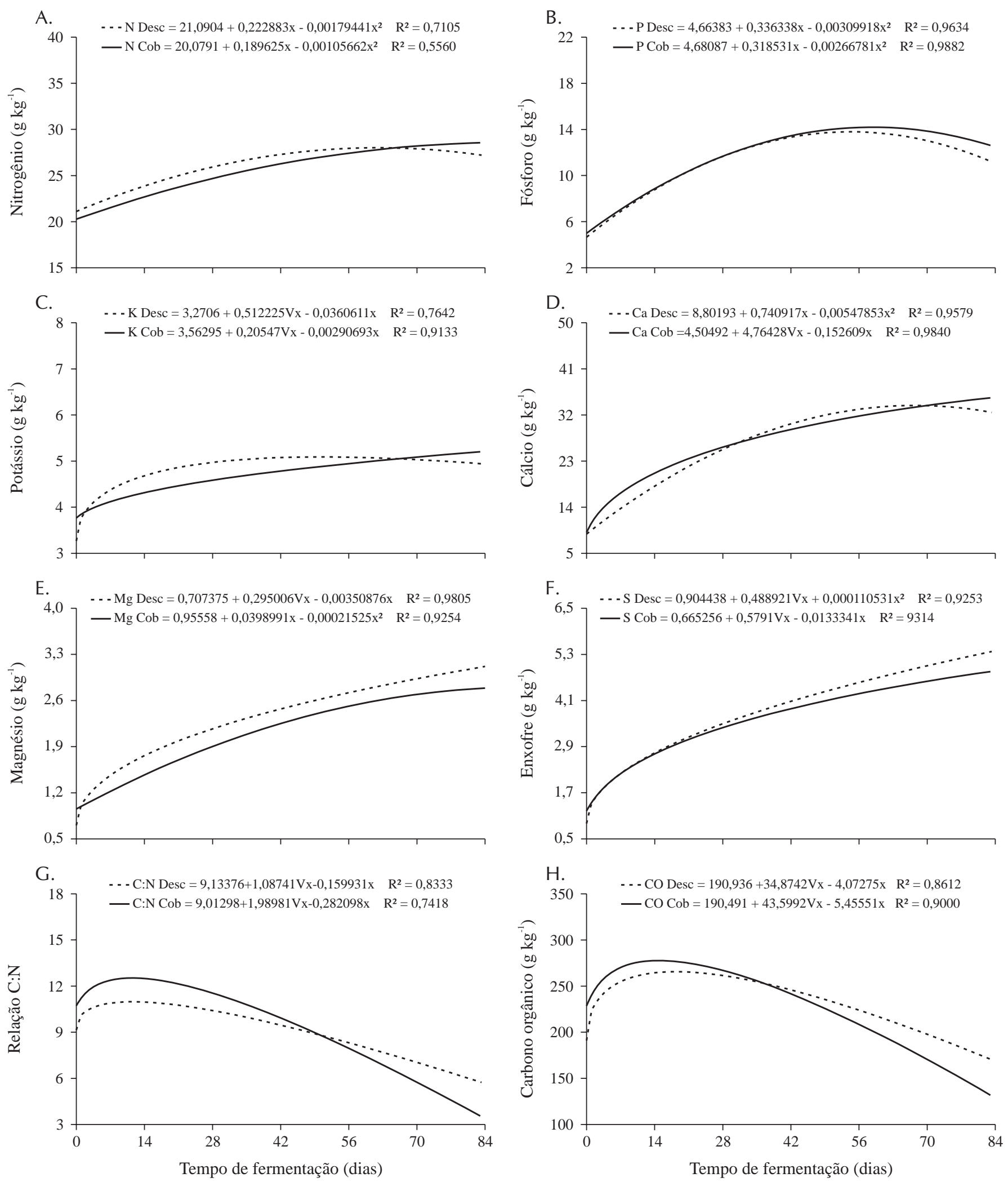

Figura 2. Concentração de macronutrientes na matéria seca e relação $\mathrm{C}: \mathrm{N}$ do esterco de suínos nos tratamentos sem cobertura e com cobertura, durante o período de fermentação

respectivamente; o teor máximo de $\mathrm{P}$ foi estimado aos 54 dias no tratamento descoberto e aos 60 dias no coberto com 13,79 e $14,19 \mathrm{~g} \mathrm{~kg}^{-1}$, respectivamente, enquanto para o $\mathrm{K}$ os teores máximos estimados foram de 5,09 e de 5,20 $\mathrm{g} \mathrm{kg}^{-1}$, aos 50 e 84 dias, no tratamento descoberto e coberto, res- pectivamente (Figura 2A, B, C e D). De modo geral, maiores concentrações de nutrientes $\mathrm{N}, \mathrm{P}, \mathrm{K}, \mathrm{Ca}, \mathrm{Mg}$ e S no esterco ocorreram com 60 dias de fermentação, período semelhante àquele em que se deu a estabilização da temperatura (Figura 1B e C), indicando maturidade do esterco e 
melhoria das características químicas. Jahnel et al. (1999), trabalhando com lixo urbano, concluíram que 52 dias de fermentação foram suficientes para a maturação do composto, com aumento nos teores de N e P e redução da relação C:N e elevação do pH. De acordo com Tiquia (2005) os dejetos de suínos alcançam a maturação aos 56 dias, se a umidade for mantida adequada, ou seja, próximo a 50\%.

A relação C:N inicial do esterco foi de 9,8:1 e, no final do processo de fermentação, constatou-se redução para 6,6:1 no tratamento com cobertura e para 5,2:1 no tratamento sem cobertura (Figura 2G). A redução na relação C:N se deve ao fato de que, no início do processo de fermentação, há predominância de produtos de fácil decomposição, o que propicia uma atividade microbiana mais intensa, com liberação de $\mathrm{CO}_{2}$ e energia na forma de calor (Jahnel et al., 1999).

De acordo com Kiehl (1985), os valores da relação C:N recomendados para que ocorra decomposição rápida e eficiente da matéria orgânica, devem estar compreendidos entre 26:1 a 35:1. Em valores inferiores ocorrem perdas praticamente inevitáveis, de $\mathrm{N}$; assim, a relação $\mathrm{C}: \mathrm{N}$ do esterco de suínos, normalmente inferior a 10:1, é considerada muito baixa. Observa-se que ao mesmo tempo em que houve perda de carbono orgânico (Figura $2 \mathrm{H}$ ), ocorreu também pequeno aumento na concentração de nitrogênio, no tratamento com cobertura e sem cobertura (Figura 2A); desta forma e apesar do esterco de suínos apresentar baixa relação $\mathrm{C}: \mathrm{N}$, não houve grande perda desse nutriente durante a fermentação chegando, ao final do processo, com teores de $\mathrm{N}$ entre 27 e $28 \mathrm{~g} \mathrm{~kg}^{-1}$ (Figura 2A).

Notou-se, também, aumento na concentração de $\mathrm{Fe}, \mathrm{Cu}$ e Mn no esterco durante a fermentação (Figura 3A, B e D), enquanto o teor de $\mathrm{Zn}$ atingiu o seu máximo aos 46 dias no tratamento descoberto e aos 37 dias no tratamento coberto, com 1164,41 e 1140,03 $\mathrm{mg} \mathrm{kg}^{-1}$, respectivamente (Figura 3C); no final do período, o teor de $\mathrm{Zn}$ foi menor no esterco tanto no tratamento descoberto $\left(110 \mathrm{mg} \mathrm{kg}^{-1}\right)$ quanto no coberto (107 $\left.\mathrm{mg} \mathrm{kg}^{-1}\right)$. A maior disponibilidade de nutrientes é conseqüência da mineralização da matéria orgânica do esterco com melhoria na qualidade dos adubos orgânicos produzidos (Sediyama et al., 2000). Variações significativas no teor de macro e micronutrientes, antes e após a fermentação de dejetos de suínos, também foram constatadas por Matos et al. (1998) e Daniel (2005).

Daniel (2005) descreve que os principais metais pesados encontrados nos dejetos de suínos, são: $\mathrm{Cu}$ e Zn, usados em grande escala nas dietas dos animais para melhor crescimento e controle de diarréia. Apesar da riqueza dos dejetos de suínos em Cu e Zn, Sediyama et al. (2000), verificaram redução nas concentrações desses elementos no final do processo de compostagem, quando as concentrações máximas de $\mathrm{Cu}$ e Zn foram $306 \mathrm{mg} \mathrm{kg}^{-1}$ e $178 \mathrm{mg} \mathrm{kg}^{-1}$ na matéria seca, respectivamente. Considerando-se que o limite máximo para a concentração de cobre é de $750 \mathrm{mg} \mathrm{kg}^{-1}$ e de zinco é $1.400 \mathrm{mg} \mathrm{kg}^{-1}$ em compostos orgânicos (Wa Doe Interim Guidelines for Compost Quality apud Beaver, 1994), pode-se concluir que as concentrações desses metais nos adubos, aos 65 dias que foram, em média, 89,66 mg kg-1 de $\mathrm{Cu}$ e $884,27 \mathrm{mg} \mathrm{kg}^{-1}$ de $\mathrm{Zn}$, se situaram dentro de padrões seguros para o uso na agricultura.

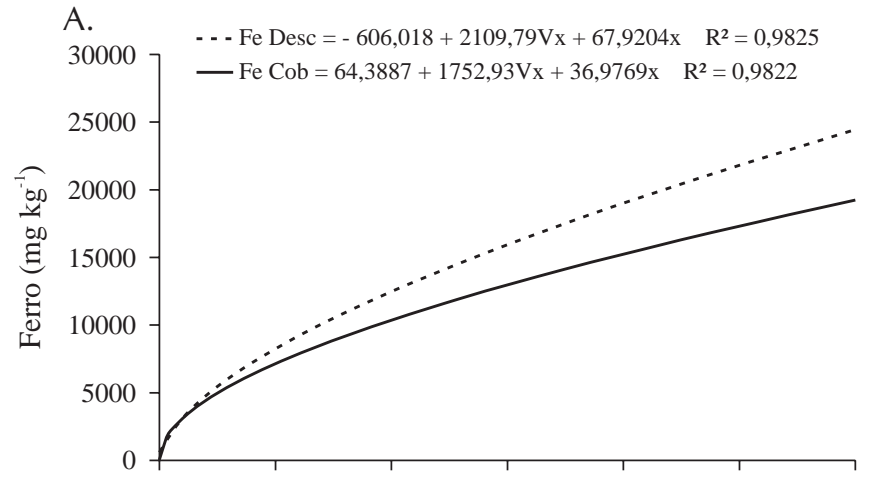

B. $\quad-$ - Cu Desc $=43,6108+0,9718 x-0,004545 x^{2} \quad R^{2}=0,9949$
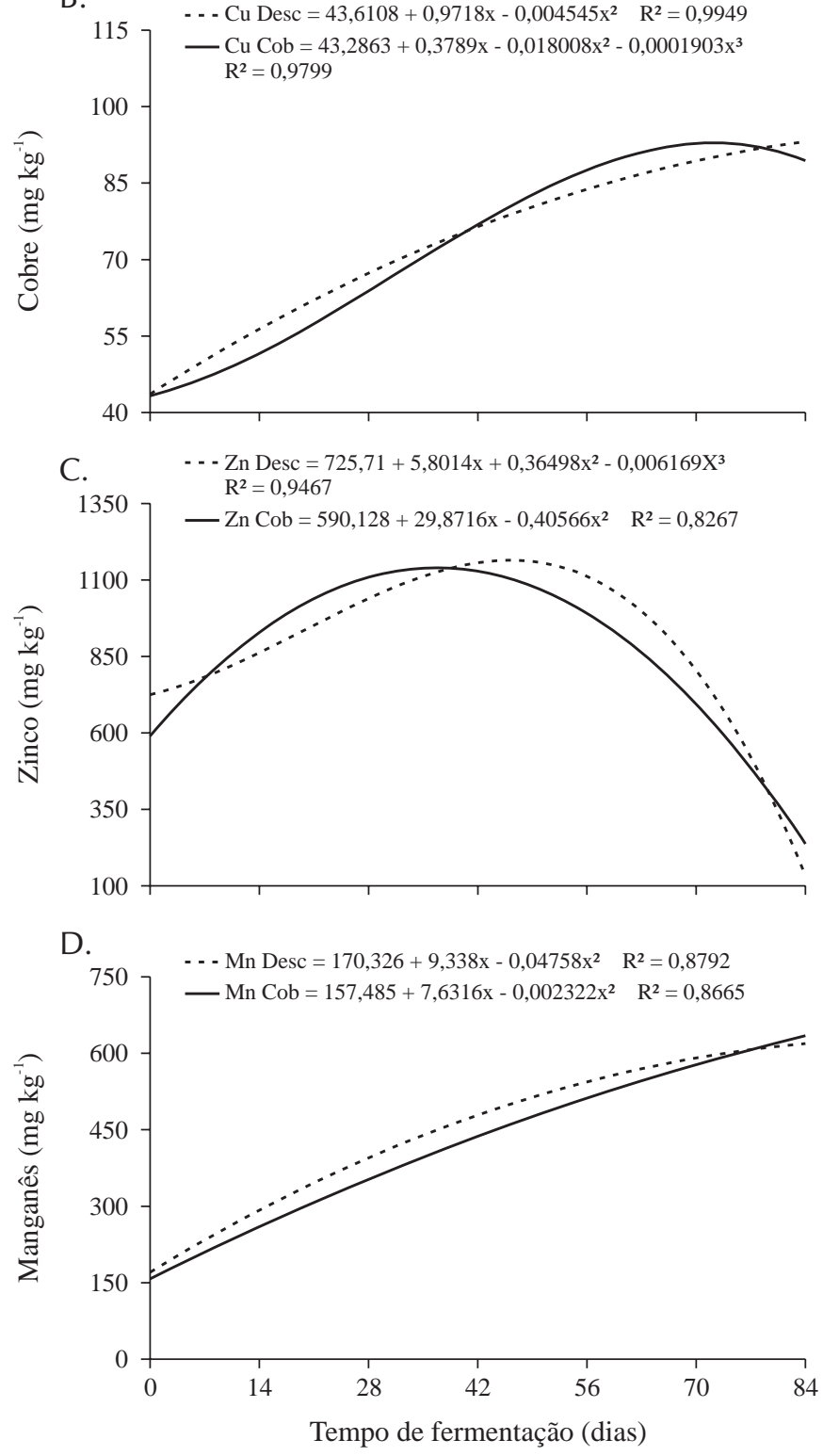

Figura 3. Concentração de micronutrientes na matéria seca do esterco de suínos nos tratamentos sem cobertura e com cobertura, durante o período de fermentação

No início da fermentação o pH foi de 5,28 e no final apresentou valor de 6,23 no tratamento descoberto e 6,47 no tratamento coberto; esses resultados estão coerentes com aqueles observados por Jahnel et al. (1999) ao constatarem, em 
composto de lixo urbano, pH próximo a 5,0 no início do processo de maturação e valores próximos a 8,5 após 52 dias de incubação. $\mathrm{O}$ baixo valor inicial de $\mathrm{pH}$ pode ser associado à presença de ácidos orgânicos existentes nos estercos que, por ação da atividade microbiana, são degradados e ocasionam aumento do pH. De acordo com Kiehl (1985), durante a compostagem em condições normais, mesmo a partir de matéria-prima ácida, ocorre aumento do pH em função da decomposição biológica sem, no entanto, haver grandes perdas de nitrogênio.

O uso de esterco fresco de suínos pode provocar, além do aquecimento pelo aumento da respiração microbiana, acidificação temporária do solo, prejudicando o desenvolvimento das plantas (Jahnel et al., 1999); por outro lado, o uso de esterco fresco pode ser fonte de contaminação de pessoas durante o manuseio, por diferentes patógenos evidenciando, assim, a necessidade de fermentação dos estercos de suínos para uso agronômico.

A população inicial de bactérias do grupo coliformes totais e fecais no esterco, no início do processo de fermentação, foi da ordem de $10^{6}$ e $10^{5} \mathrm{UFC} \mathrm{g}^{-1}$, respectivamente. Com 16 dias de fermentação ocorreu redução aproximada de 1,5 ciclo logaritmo da população de coliformes totais no esterco manejados sem cobertura e de quase 3,0 ciclos no esterco manejado com cobertura (Figura 4); após este período, a população de coliformes totais foi reduzida em ambos os tratamentos e atingiu, com 64 dias de fermentação, uma redução de três ciclos logaritmos (99,90\%) no tratamento sem cobertura e superior a quatro ciclos logaritmos $(99,99 \%)$ no sistema manejado com cobertura (Figura 4).

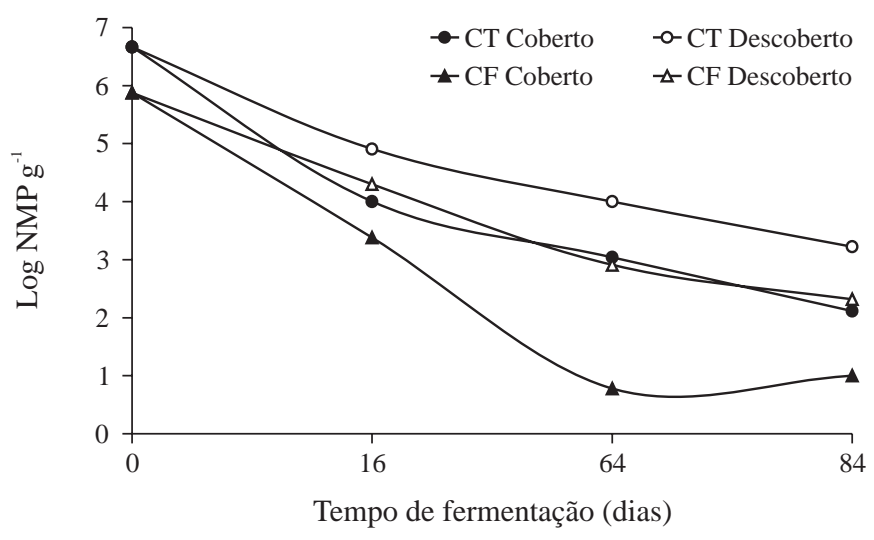

Figura 4. Logaritmo do número de coliformes totais (CT) e coliformes fecais (CF) no esterco de suínos nos tratamentos sem cobertura e com cobertura, durante o período de fermentação

A redução da população de coliformes fecais ou termotolerantes, seguiu a mesma tendência da redução da população de coliformes totais com 16 dias de fermentação no tratamento sem e com cobertura; entretanto, com 64 dias de fermentação ocorreu redução acentuada da população de coliformes fecais no dejeto coberto, comparado com o sistema sem cobertura com diferença de aproximadamente dois ciclos logaritmos.
Aos 84 dias de fermentação observou-se redução na população de coliformes totais de três ciclos logaritmos no tratamento sem cobertura e superior a quatro ciclos no tratamento coberto. Para coliformes fecais notou-se redução de três ciclos logaritmos no tratamento sem cobertura e de cinco ciclos no tratamento manejado com cobertura, cujos resultados indicam a maior eficiência do processo de fermentação do dejeto com cobertura para a redução desses grupos microbianos. Em ambos os tratamentos as contagens de coliformes fecais foram inferiores a $10^{3} \mathrm{NMP} \mathrm{g}^{-1}$ de esterco no final da fermentação (Figura 4), resultados semelhantes aos obtidos por Schmidt (2002) que constatou valores de redução da ordem de $99 \%$, para coliformes totais e fecais em estação de tratamento de dejeto de suínos, mas até o momento não existe uma legislação que regulamente o uso de esterco de suínos na agricultura, especialmente quanto às características microbiológicas; já o lodo de esgoto classificado como tipo $\mathrm{A}$, que apresenta concentração de coliformes termotolerantes $<10^{3} \mathrm{NMP} \mathrm{g}^{-1}$ de substrato, não pode ser usado como adubo orgânico para a produção de hortaliças, pastagens, tubérculos e raízes, nem as demais culturas cuja parte comestível entre em contato com o solo (CONAMA, 2006).

Em estudos com adubação à base de esterco de suínos e de outros animais, dever-se-ia levar em consideração, também, o tempo de permanência no solo, pois Matos et al. (1997) avaliaram a permanência de coliformes fecais no solo e concluíram que a sobrevivência de bactérias do grupo coliforme foi inferior a duas semanas; deste modo, mais estudos sobre o manejo e tratamento dos dejetos de suínos devem ser realizados para melhor subsidiar uma legislação sobre a utilização de esterco de suínos como adubo orgânico.

A presença dos patógenos Salmonella sp e Listeria monocytogenes não foi constatada nas amostras de esterco coletadas no início e durante o processo de fermentação, para ambos os tratamentos. Verificou-se adequação das amostras ao se compará-las com a legislação para lodo de esgoto (CONAMA, 2006) que estabelece a ausência de Salmonella sp em $10 \mathrm{~g}$ de amostra.

A estabilização do esterco de suínos ocorreu em ambos os tratamentos; a adoção do sistema de fermentação do esterco em pilhas com ou sem cobertura, vai depender da época do ano, sendo o manejo descoberto mais apropriado para a época seca com irrigação complementar, para a maturação do esterco de suínos e obtenção de adubo orgânico com características química, física e microbiológica adequadas para a agricultura. De acordo com as características temperatura, relação $\mathrm{C}: \mathrm{N}$, pH e concentração de nutrientes, constatou-se que a estabilização do esterco de suínos ocorreu com 60 a 65 dias de fermentação, reforçando-se a necessidade da etapa de estabilização do esterco de suínos antes do seu uso como adubo orgânico.

Observou-se, no final do processo de fermentação, redução do volume das pilhas em torno de $50 \%$ do inicial. A coloração do esterco ficou bem mais escura e houve redução significativa do odor e da umidade o que, em geral, facilita o manuseio e o transporte para a área de cultivo. 


\section{CONCLUSÕES}

1. Pela análise das características temperatura, relação $\mathrm{C}: \mathrm{N}$ e pH, verificou-se que o tempo de fermentação de 65 dias foi considerado suficiente para maturação do esterco com características químicas e físicas adequadas.

2. Ocorreu aumento na concentração de nutrientes, exceto do zinco, durante a fermentação, o que melhorou a qualidade do esterco de suínos.

3. O período de 84 dias de fermentação foi suficiente para reduzir a população de coliformes, da ordem de 99,90\%, comparada com a população inicial.

4. Não se constatou presença de Salmonella sp e Listeria monocytogenes em nenhuma das amostras do esterco de suínos em fermentação.

\section{AgRADECIMENTOS}

À Fundação de Amparo à Pesquisa do Estado de Minas Gerais - FAPEMIG, pelo apoio financeiro ao projeto e concessão de bolsas de pesquisa nas modalidades: Iniciação Científica e Desenvolvimento Tecnológico Industrial e, ao CNPq, a bolsa de produtividade ao primeiro autor.

\section{LITERATURA CITADA}

Amorim, A. C.; Lucas Júnior, J.; Resende, K. T. Compostagem e vermicompostagem de dejetos de caprinos: Efeito das estações do ano. Engenharia Agrícola, v.25, n.1, p.57-66. 2005.

APHA - American Public Health Association. Compendium of methods for the microbiological examination of foods. 3.ed., Washington: APHA, 1992. 913p.

Beaver, T. Pilot study of coal ash compost. Compost Science and Utilization, v.2, n.3, p.18-21, 1994.

CONAMA - Conselho Nacional do Meio Ambiente. Resolução $n^{0}$ 375/2006. Diário Oficial da República Federativa do Brasil. 30 de agosto de 2006. http://www.sedur.ba.gov.br/WEBFNSS/fnss/ noticia_04-09-2006.htm. 15 Fev. 2007.

Cunha, T. J. F.; Blancaneaux, P.; Calderano Filho, B.; Carmo, C. A. F. S.; Garcia, N. C. P.; Lima, E. M. B. Influência da diferenciação pedológica no desenvolvimento da seringueira no município de Oratórios, MG. Pesquisa Agropecuária Brasileira, v.35, n.1, p.145-155. 2000.
Daniel, G. Controle da poluição proveniente dos dejetos da suinocultura, reaproveitamento e valoração dos subprodutos. Curitiba: PUC, 2005. 59p. Trabalho Conclusão Curso

Jahnel, M. C.; Melloni, R.; Cardoso, E. J. B. N. Maturidade de composto de lixo urbano. Scientia Agrícola, v.56, n.2, p.301-304. 1999.

Kiehl, J. E. Fertilizantes orgânicos. Piracicaba: Agronômica Ceres, 1985. 492p.

Konzen, E. A. Manejo e utilização de dejetos suínos. Concórdia: Embrapa-CNPSA, 1983. 32p. Circular Técnica, 6

Matos, A. T.; Sediyama, M. A. N. Riscos potenciais ao ambiente pela aplicação de dejeto líquido de suínos ou compostos orgânicos no solo. In: Seninário Mineiro Sobre Manejo e Utilização de Dejetos de Suínos, 1, Ponte Nova. Anais... Viçosa: EPAMIG, 1995. p.45-54.

Matos, A. T.; Sediyama, M. A. N.; Freitas, S. P.; Vidigal, S. M.; Garcia, N. C. P. Características químicas e microbiológicas do solo influenciadas pela aplicação de dejeto líquido de suínos. Revista Ceres, v.44, n.254, p.399-410, 1997.

Matos, A. T.; Vidigal, S. M.; Sediyama, M. A. N.; Garcia, N. C. P.; Ribeiro, M. F. Compostagem de alguns resíduos orgânicos utilizando-se águas residuárias da suinocultura como fonte de nitrogênio. Revista Brasileira de Engenharia Agrícola e Ambiental, v.2, n.2, p.199-203, 1998.

Schmidt, V. Sobrevivência de microorganismos mesófilos e perfil físico-químico e estação de tratamento de dejetos suínos. Acta Scientiae Veterinariae, v.30, n.3, p.205-206, 2002.

Sediyama, M. A. N.; Garcia, N. C. P.; Vidigal, S. M.; Matos, A. T. Nutrientes em compostos orgânicos de resíduos vegetais e dejetos de suínos. Scientia Agricola, v.57, n.1, p.185-189, 2000.

Silva, F. C. da. Manual de análises químicas de solos, plantas e fertilizantes. Brasília: EMBRAPA, 1999. 370p.

Silva, N.; Junqueira, V. C. A.; Silveira, N. F. A. Manual de métodos de análise microbiológica de alimentos. São Paulo: Varela, 1997. 295p.

Tam, N. F. Y.; Tiquia, S. Assessing toxicity of spent pig litter using a seed germination technique. Resources, Conservation and Recycling, v.11, p.261-274, 1994.

Tiquia, S. M. Microbiological parameters as indicators of compost maturity. Journal of Applied Microbiology, v.99, n.4, p.816-28. 2005.

Wu, L.; Ma, L. Q. Effects of sample storage on biosolids compost stability and maturity evaluation. Journal of Environmental Quality, v.30, p.222-228. 2001. 